\title{
Behavioral contrast in rats with an operant licking response
}

\author{
CHARLES F. FLAHERTY, J. ANTHONY CLANCY, and PETER S. KAPLAN \\ Rutgers University, New Brunswick, New Jersey 08903
}

\begin{abstract}
Access to a sucrose tube was made contingent upon licks on an empty glass tube. After training on a mult VI 45/VI 45 schedule, separate groups of rats were shifted to either a mult VI 45/ext or a mixed VI 45/ext schedule. Illumination or nonillumination of the operant tube was used as the discriminative stimulus for the multiple group. Substantial stimulus control and behavioral contrast was demonstrated in the multiple-schedule group, but an equivalent increase in response rate was shown in the mixed group. Behavioral contrast was attributed to decrease in reinforcement density subsequent to the shift rather than to behaviors elicited by the predictive value of $\mathrm{S}+$.
\end{abstract}

When reinforcement schedules are shifted from equal to unequal by a change in one component of a multiple schedule, rate of responding in both components often changes in a systematic fashion. Of particular interest has been response-rate changes in the presence of the unshifted component. These changes are referred to as behavioral contrast if the response-rate change in the unshifted component is in a direction opposite to that occurring in the shifted component (Reynolds, 1961). However, there are conditions under which response rate in the shifted component does not change, but response rate in the unshifted component does change in a direction opposite to the shift in reinforcement rate in the shifted component (e.g., Bloomfield, 1967; Halliday \& Boakes, 1974). These changes also have been referred to as behavioral contrast.

Behavioral contrast has been a topic of considerable research and theoretical activity, yet there is no formulation that seems to encompass all of the phenomena included under the behavioral contrast rubric (Hearst \& Gormley, 1976; Hinson \& Staddon, 1978; Rachlin, 1973; Schwartz \& Gamzu, 1977; Williams, 1979).

The present paper is concerned with an initial exploration of behavioral contrast in rats with a novel responsereinforcement arrangement: Rats were required to make operant licks on an empty glass tube, configured to record licks and provide lick-contingent feedback, in order to receive liquid sucrose reinforcement, also made available in a tube.

\section{METHOD}

\section{Subjects}

Eight naive male Sprague-Dawley-derived rats were used as subjects. The animals were maintained at $82 \%$ of their freefeeding weights and were housed individually under a 14/10 light/dark cycle.

\section{Apparatus}

Training was conducted in a Plexiglas chamber measuring $30 \times 25 \times 25 \mathrm{~cm}$. On one side of the chamber, there were two holes spaced $11 \mathrm{~cm}$ apart and $4 \mathrm{~cm}$ above the wire-mesh floor.
One of these holes was $1.5 \mathrm{~cm}$ in diameter and provided access to a modified glass drinking tube. This tube (hereafter termed the "operant" tube) was constructed by cutting a segment $2 \mathrm{~cm}$ long from the drinking end of a standard glass drinking tube and filling the opening in the drinking end with melted solder, which, at the same time, was used to anchor a small wire drawn out through the back of the tube. The solder and wire constituted one side of a contact relay circuit, the other side of which was wired to the hardware cloth floor of the chamber. The contact relay circuit was wired to programming equipment located in an adjacent room for the recording of operant licks. In addition, a second contact relay amplifier was attached to the operant tube and located just outside the Plexiglas chamber. The purpose of this second circuit was to provide auditory feedback (clicks) to the rat whenever it made contact with the solder surface of the operant tube. Visual feedback was also provided by the flash of an amber light located next to the contact relay and operated by the relay.

Inside the operant tube was a small bulb, the illumination or nonillumination of which was used as the discriminative stimulus. The operant tube was mounted so that the solder surface was flush with the inside wall of the chamber.

Located $11 \mathrm{~cm}$ to the right of the access hole containing the operant tube was a second access hole, $1 \mathrm{~cm}$ in diameter, through which a metal drinking tube was attached to a graduated cylinder. This tube was used to provide access to a sucrose solution whenever a reinforcement was scheduled.

\section{Procedure}

The rats were given 1 day of magazine training, which con sisted of 10 exposures to the sucrose tube made available on a VI 45-sec schedule. On each exposure, the rat was allowed a 10 -sec access period, beginning with the first lick. A $20 \%$ (by weight: sucrose/sucrose + water) sucrose solution was used as the reinforcement.

On the next day, the operant tube was introduced and the rats were allowed 10 reinforcements ( $10 \mathrm{sec}$ access each) on a CRF schedule. No hand shaping was employed. The CRF schedule was continued for a total of 5 days. The remainder of training progressed as follows: 2 days FR $2 ; 1$ day each FR 3, FR 5 , FR 7, FR 10; 3 days FR 11; 6 days VI $30 \mathrm{sec} ; 12$ days VI $45 \mathrm{sec}$. During the VI periods, session length was $12 \mathrm{~min}$ and the light in the operant tube alternated on and off every $2 \mathrm{~min}$. There were two VI tapes of each value ( $30 \mathrm{sec}$ and $45 \mathrm{sec}$ ), and these were alternated across sessions. Each tape was prepared according to the Catania formula (Catania \& Reynolds, 1968). The 12 days of VI 45/VI 45 training was considered as baseline for the subsequent shift to a differential multiple schedule. 
On the day following the $12^{\text {th }}$ VI $45 /$ VI 45 baseline day, four of the rats were shifted to a mult VI 45/ext schedule. For half the animals in this group, light on in the operant tube served as $\mathrm{S}^{+}$and light off as $\mathrm{S}^{-}$; the remaining animals had the reversed conditions. Session length was increased to $24 \mathrm{~min}$, but the discriminative stimuli continued to alternate every $2 \mathrm{~min}$.

The remaining four animals were shifted to a type of mixed schedule. That is, they were shifted from the baseline VI 45/VI 45 condition to a mixed VI 45/ext schedule. However, the light-on/ light-off condition of the tube continued to be presented, but these cues were uncorrelated with the reinforcement contingencies. Session length was the same for these animals as for the mult group, but rate of stimulus alternation was different. The light-on/light-off conditions were maintained for either 2-min or 4-min periods, and these varied in a random fashion with the restriction that total length of each be equivalent in each session and that the time that each lighting condition was paired with each reinforcement condition be equal during a session. Thus, the stimuli present for the "mixed" group were not predictive of reinforcement availability.

\section{RESULTS}

The mean number of reinforcements earned per session remained at approximately 14 in all experimental phases for both groups.

Response rates for each of the four rats in the mult VI/ ext condition are presented in Figure 1. The switch from baseline VI 45/VI 45 to the multiple schedule was accompanied by a clear rise in rate of responding in the presence of the $\mathrm{S}^{+}$in three of the four rats. There was, however, an indication of a decline in rate of responding in the presence of $\mathrm{S}^{-}$in only two of the rats (Rats 44 and 46), and this decline was not substantial.

These same data, with response rate during the shift expressed as a ratio of baseline response-rate, are presented as group means in the left panel of Figure 2. These data indicate clearly the development of stimulus control and the rise in $\mathrm{S}^{+}$responding above the baseline level, whereas $\mathrm{S}^{-}$responding remains near the original baseline rate. Analysis of variance on these data indicate a reliable difference between $\mathrm{S}^{+}$and $\mathrm{S}^{-}$responding $[\mathrm{F}(1,39)=37.29, \mathrm{p}<.001]$.

It is also evident in Figures 1 and 2 that the return to baseline conditions for 13 sessions did not return response rates to the original baseline. A second shift to the mult VI/ext schedule produced another rise in response rate, but one that exceeded the second baseline in only two of the four rats.

The data obtained from the animals exposed to the "mixed" schedule are presented in Figure 3 and in the right-hand panel of Figure 2. It is evident that these animals did not show any sign of stimulus control, as would be expected, but it is also evident that these animals showed a rise in response rate when the shift to the mixed schedule was introduced. In the case of both the mult and mixed animals, the rise in response rate occurring during the shift was discontinuous with the baseline function, with the possible exception of one rat under each condition (Rats 60 and 70). The dip in response rate occurring in the mixed group was the result of a combination of apparatus failure and overfeeding of the animals. This drop does not seem to

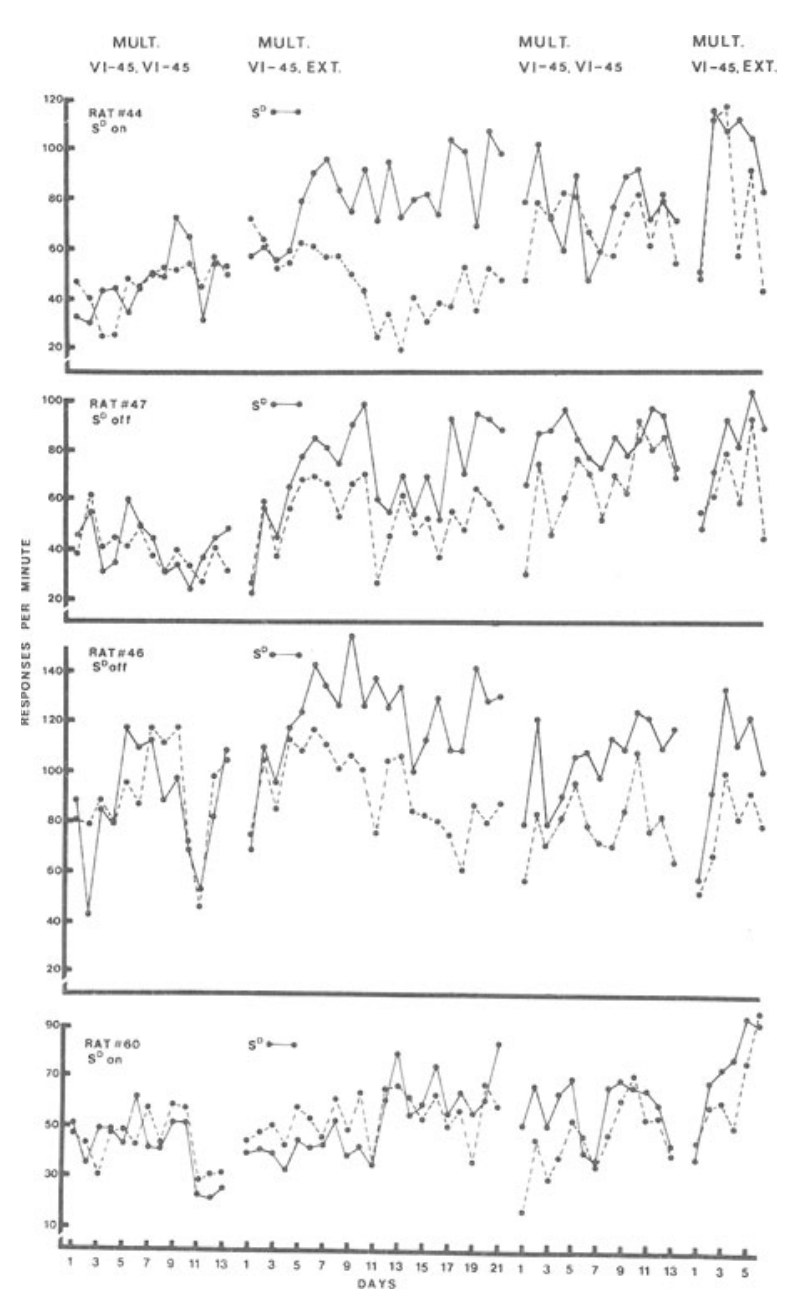

Figure 1. Response rate to operant tube as a function of experimental conditions in four rats exposed to multiple schedules. For two of the rats, $\mathrm{S}^{+}$was the illumination of the operant tube ("on"). For the other rats, this was the $S^{-}$.

obviate any of the conclusions that may be drawn from these data.

The animals exposed to the mixed schedule showed a drop in response rate when baseline conditions were reinstituted, but, as in the case of the animals exposed to the multiple schedule, this drop was not sufficient to return the animals to baseline response rates. There was also a tendency for response rates to rise above the second baseline when the mixed schedule was reintroduced, but this was pronounced in only two of the animals.

A comparison of the rates obtained during the shift phases by the animals exposed to multiple and mixed schedules is most readily obtained in Figure 2 . It is clear that there was no tendency for the response rates occurring under $\mathrm{S}^{+}$conditions in the animals exposed to the multiple schedule to exceed the overall response rate of the animals exposed to the "mixed" schedule. If anything, response rates under the latter schedule tended to be slightly higher. 

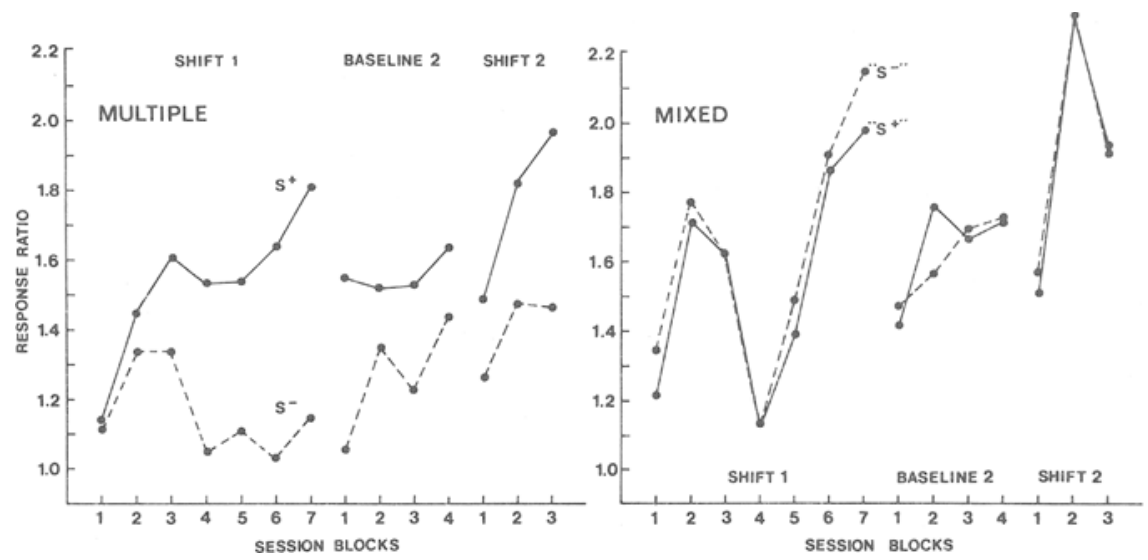

Figure 2. Mean response ratios for the multiple and mixed groups as a function of experimental conditions. The ratios were obtained by dividing response rates for each shift session by preshift baseline response rates for each rat.
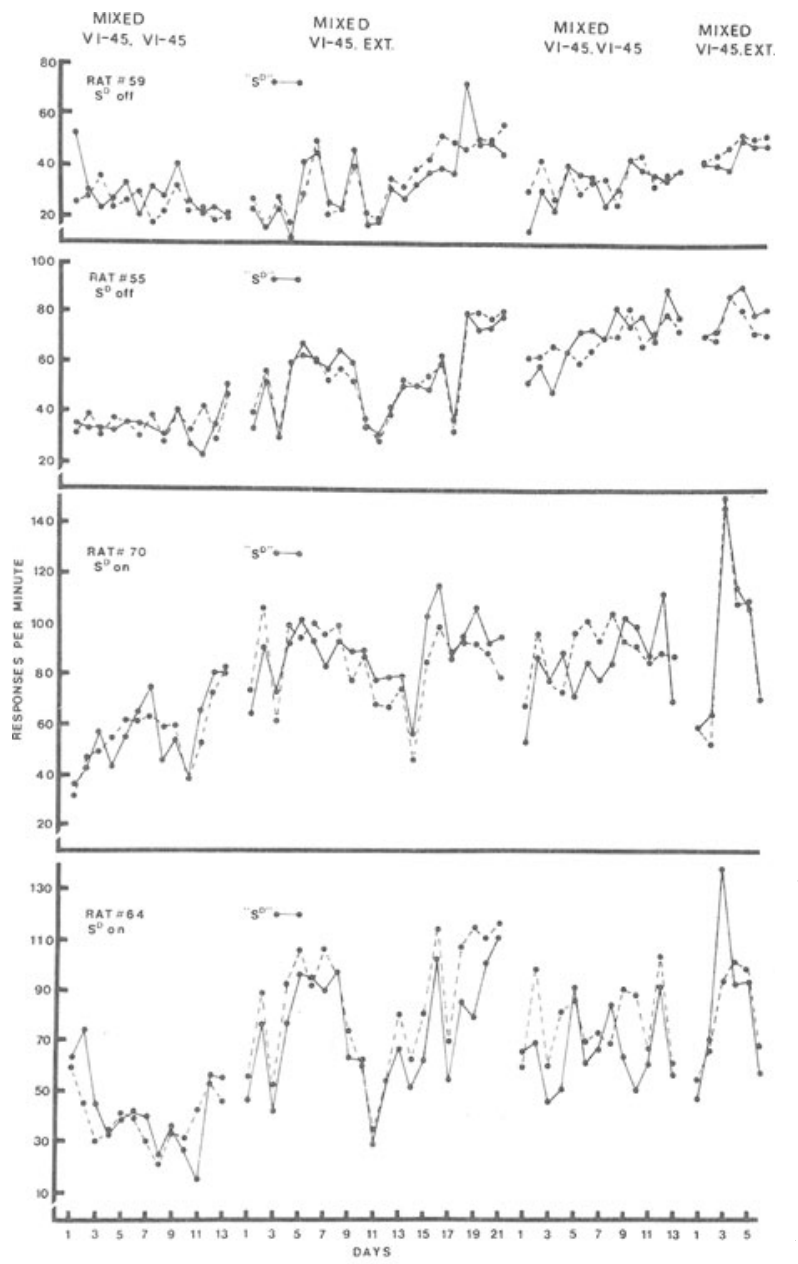

Figure 3. Response rate to the operant tube as a function of experimental conditions in four rats exposed to mixed schedules. These rats received the light-on and -off stimuli, but these stimuli were uncorrelated with reinforcement.

\section{DISCUSSION}

If behavioral contrast in multiple VI schedules may be defined in terms of response-rate changes in the unshifted component in a direction away from reinforcement rate changes in the shifted component (cf. Bloomfield, 1967; Halliday \& Boakes, 1974), then the present study demonstrates behavioral contrast in rats with an operant licking response. More systematic and detailed studies of the operant lick response may indicate whether the general failure of $\mathrm{S}^{-}$responding to extinguish in multiple schedules is a characteristic of the operant licking response or an accident of the particular parameters used here.

The occurrence of behavioral contrast in the absence of a substantial decline in $\mathrm{S}^{-}$response rates in the present and earlier studies (e.g., Halliday \& Boakes, 1974) has relevance for a recent theory of behavioral contrast. Hinson and Staddon (1978) have argued that behavioral contrast is due simply to reallocation of available responses, a greater share going to the criterion operant response in the presence of the unchanged component. This may be reasonable, but studies like the present one indicate that these "extra" responses may come entirely from interim or adjunctive behavior. It is not necessary that the time allocated to $S^{-}$responding be reduced in order to obtain contrast in $\mathrm{S}^{+}$.

Finally, the present results speak to the usual definition of behavioral contrast. The discontinuity in response rates to $\mathrm{S}^{+}$ between first baseline and first shift indicates contrast occurred in the present experiment, in terms of the usual procedure of defining contrast in terms of a comparison of $\mathrm{S}^{+}$responding with preshift baseline. However, a number of investigators (e.g., Mackintosh, 1974) have argued for the inclusion of control groups in order to insure that contrast has indeed occurred. One such control, the maintenance of some animals on the original VI/VI schedule was not included in the present experiment. But, again referring to the fairly abrupt increase in response rates following the shift, it seems likely that contrast, defined in terms of a comparison with such unshifted animals, would still have occurred in the present experiment.

The control group that was included, the "mixed" group, is one that controls for the effects of shift in overall reinforcement density (cf. Hearst \& Gormley, 1976). The fact that the mixed group in the present experiment showed a rise in response rate at least as great as the mult group following the reinforcement shift indicates that the contrast obtained in the present experiment, as defined in terms of baseline comparisons, is related to 
the decrease in reinforcement density, or an overall change for the worse (Bloomfield, 1969; Scull, Davies, \& Amsel, 1970), rather than to elicited behaviors directed toward the $\mathrm{S}^{+}$stimulus (Schwartz \& Gamzu, 1977).

\section{REFERENCES}

Bloomfield, T. M. Some temporal properties of behavioral contrast. Journal of the Experimental Analysis of Behavior, $1967,10,159-164$.

Bloomfield, T. M. Behavioral contrast and the peak shift. In R. M. Gilbert \& N. S. Sutherland (Eds.), Animal discrimination learning. London: Academic Press, 1969.

Catania, A. C., \& Reynolds, G. A quantitative analysis of the responding maintained by interval schedules of reinforcement. Journal of the Experimental Analysis of Behavior, 1968, 11, 327-383.

Halliday, M. S., \& Bonkes, R. A. Behavioral contrast without response-rate relations. Journal of the Experimental Analysis of Behavior, 1974, 33, 453-462.

Hearst, E., \& Gormley, D. Some tests of the additivity (autoshaping) theory of behavioral contrast. Animal Learning \& Behavior, 1976, 4, 145-150.
Hinson, J. M., \& Staddon, J. E. R. Behavioral competition: A mechanism for schedule interactions. Science, 1978, 202, 432-434.

MAckintosh, N. J. The psychology of animal learning. London: Academic Press, 1974.

Rachlin, H. Contrast and matching. Psychological Review, 1973, 80, 217-234.

REYNOLDS, G. S. Behavioral contrast. Journal of the Experimental Analysis of Behavior, 1961, 4, 51-71.

Schwartz, B., \& Gamzu, E. Pavlovian control of operant behavior: An analysis of autoshaping and its implications for operant conditioning. In W. K. Honig \& J. E. R. Staddon (Eds.), Handbook of operant behavior. New York: AppletonCentury-Crofts, 1977.

Scull, J., Davies, K., \& Amsel, A. Behavioral contrast and frustration effect in multiple and mixed fixed-interval schedules in the rat. Journal of Comparative and Physiological Psychology, $1970,71,478-483$.

Williams, B. A. Contrast, component duration, and the following schedule of reinforcement. Journal of Experimental Psychology: Animal Behavior Processes, 1979, 5, 379-396.

(Received for publication May 19, 1981.) 